\title{
O Abastecimento de Água nas Favelas em Meio à Pandemia da Covid-19 1,2
}

Rute Imanishi Rodrigues ${ }^{3}$

Neste artigo, aborda-se a questão do abastecimento de água nos assentamentos urbanos precários no contexto da pandemia da Covid-19. Atualmente, estima-se que 5 milhóes de domicílios no país situam-se em áreas de "aglomerados subnormais", o que, nas estatísticas do Instituto Brasileiro de Geografia e Estatística (IBGE), ${ }^{4}$ compreendem favelas, palafitas, loteamentos irregulares e assemelhados. ${ }^{5}$ As regióes metropolitanas das capitais abrigam mais de $80 \%$ destes assentamentos, o que reflete as dificuldades da populaçáo de baixa renda para morar nas áreas regularizadas das grandes cidades, devido aos altos preços de aluguel e venda de imóveis.

Embora não existam dados atualizados sobre o acesso à água tratada nas favelas, o censo de 2010 mostra que, na maior parte das regióes metropolitanas, mais de $90 \%$ dos domicílios nesses assentamentos estão conectados à rede geral de água, com exceção das favelas na região Norte e algumas metrópoles do Nordeste e Centro-Oeste, onde o grau de acesso é mais baixo, conforme mostra a tabela 1. É possível afirmar que tais indicadores positivos na maioria das metrópoles refletem décadas de políticas de urbanização e implantação de redes de saneamento básico, como será visto ao longo deste texto. Porém, a despeito dos avanços no acesso à rede geral de água, duas dificuldades se sobressaem: i) a existência de localidades/setores sem conexão à rede de água dentro de favelas consolidadas, embora estas apresentem alto grau de acesso à rede geral; e ii) a intermitência no fornecimento de água em diversas favelas, inclusive em muitas daquelas com elevado grau de conexão à rede geral. ${ }^{6}$

As mobilizaçôes dos moradores de favelas no início da pandemia evidenciaram esses problemas que já vinham sendo relatados em pesquisas de campo - para o grande público. Assim, quando as diretivas das autoridades sanitárias preconizavam que todos deveriam "ficar em casa" e "lavar as mãos com frequência”, vídeos compartilhados na internet por moradores mostravam torneiras secas, senhoras carregando baldes de água, assim como as estratégias de armazenamento de água durante a madrugada, como o dia a dia nas favelas durante a pandemia, em imagens que foram amplificadas pela mídia. ${ }^{7}$

Em São Paulo, por exemplo, representantes das associações de moradores de uma das maiores favelas da capital, Paraisópolis, denunciaram haver racionamento permanente de água na comunidade. Note-se que essa favela registrava praticamente a totalidade de seus domicílios conectados à rede geral em 2010 (13.038 de 13.071 domicílios), segundo a Nota Técnica no 1/2020 do IBGE.

1. DOI: http://dx.doi.org/10.38116/bapi25art8

2. A autora agradece os comentários e sugestões de Cleandro Henrique Krause, que foram incorporados ao texto.

3. Técnica de planejamento e pesquisa na Diretoria de Estudos e Políticas do Estado, das Instituições e da Democracia (Diest) do Ipea.

4. Disponível em: <https://www.ibge.gov.br/geociencias/organizacao-do-territorio/tipologias-do-territorio/15788-aglomerados-subnormais. html?=\&t=acesso-ao-produto $>$.

5. Em Rodrigues (2020) há os dados para 2019.

6. Além das evidências apresentadas pela imprensa e pelas redes sociais durante a pandemia, diversos pesquisadores de campo, assim como estudos de caso, já apontavam essa situação, inclusive solicitando a inclusão da variável de frequência do abastecimento de água nas pesquisas do IBGE, o que ocorreu recentemente (Oliveira e Valla, 2001).

7. Disponível em: <https://globoplay.globo.com/v/8426688/>; <https://www.youtube.com/watch?v=BbTDAjoKuww>. 
Porém, segundo as denúncias, em Paraisópolis todos os dias, a partir de determinada hora da noite, o fornecimento de água era cortado até a manhã do dia seguinte, configurando uma situação de "racionamento velado". ${ }^{8}$ No Rio de Janeiro, a Ouvidoria Externa da Defensoria Pública do estado recebeu 550 denúncias de falta de água permanente ou regular em 143 lugares entre favelas e bairros de 14 municípios. ${ }^{9} \mathrm{Na}$ capital, favelas como Tabajara, Rocinha, Alemão e Maré, todas com elevado grau de conexão à rede geral, estiveram entre as que mais reclamaram.

TABELA 1

Aglomerados subnormais: domicílios com acesso à rede geral de água (2010) (Em \%)

\begin{tabular}{|c|c|c|c|c|}
\hline Grande Região & Região metropolitana & $\begin{array}{l}\text { Domicílios com acesso à } \\
\text { rede geral de distribuição }\end{array}$ & Capital & $\begin{array}{l}\text { Domicílios com acesso à } \\
\text { rede geral de distribuição }\end{array}$ \\
\hline \multirow{7}{*}{ Norte } & - & - & Porto Velho & 30,0 \\
\hline & - & - & Rio Branco & 46,3 \\
\hline & Manaus & 57,7 & Manaus & 56,2 \\
\hline & - & - & Boa Vista & 58,8 \\
\hline & Belém & 61,3 & Belém & 77,4 \\
\hline & Macapá & 85,8 & Macapá & 87,8 \\
\hline & - & - & Palmas & - \\
\hline \multirow{9}{*}{ Nordeste } & São Luís & 65,9 & São Luís & 60,4 \\
\hline & - & - & Teresina & 93,4 \\
\hline & Fortaleza & 92,7 & Fortaleza & 92,7 \\
\hline & Natal & 97,5 & Natal & 97,5 \\
\hline & João Pessoa & 98,9 & João Pessoa & 99,0 \\
\hline & Recife & 87,4 & Recife & 90,9 \\
\hline & Maceió & 81,0 & Maceió & 81,0 \\
\hline & Aracaju & 96,2 & Aracaju & 98,4 \\
\hline & Salvador & 98,4 & Salvador & 98,7 \\
\hline \multirow{4}{*}{ Sudeste } & Belo Horizonte & 99,4 & Belo Horizonte & 99,6 \\
\hline & Vitória & 98,6 & Vitória & 99,2 \\
\hline & Rio de Janeiro & 93,7 & Rio de Janeiro & 96,4 \\
\hline & São Paulo & 97,3 & São Paulo & 97,8 \\
\hline \multirow{3}{*}{ Sul } & Curitiba & 98,5 & Curitiba & 98,7 \\
\hline & Florianópolis & 97,7 & Florianópolis & 97,4 \\
\hline & Porto Alegre & 96,9 & Porto Alegre & 98,1 \\
\hline \multirow{4}{*}{ Centro-Oeste } & - & - & Campo Grande & 98,6 \\
\hline & Vale do Rio Cuiabá & 94,9 & Cuiabá & 94,9 \\
\hline & Goiânia & 82,1 & Goiânia & 82,1 \\
\hline & - & - & Brasília & 94,5 \\
\hline Brasil & & 88,3 & & \\
\hline
\end{tabular}

Fonte: IBGE, 2010.

Elaboração da autora.

8. Disponivel em: <https://www.youtube.com/watch?v=LSxod8dCDy4>; <https://www.youtube.com/watch?v=3haovydzz9A $>$.

9. Disponível em: <https://coronavirus.rj.def.br/liminar-garante-abastecimento-de-agua-em-comunidades/>. 
Tais mobilizações também foram organizadas por entidades de âmbito nacional, como o Observatório Nacional dos Direitos à Água e ao Saneamento (ONDAS). Ele lançou uma carta aberta na qual demandava do poder público a implementação de dez medidas emergenciais e estratégicas relativas ao saneamento e ao acesso à água para reduzir os impactos da crise nos segmentos mais vulneráveis da população. ${ }^{10}$ Tais medidas foram endossadas pelo relator para o direito à água no âmbito das Nações Unidas.

Entretanto, o que explica a aparente incompatibilidade entre os indicadores de acesso à água tratada e as reclamaçóes dos moradores de favelas? Em primeiro lugar, cabe observar que, se por um lado os programas de urbanização e implantação de redes saneamento básico em favelas têm sido pontuais e descontínuos, o processo de formação e reprodução das favelas, pelo contrário, mostra-se generalizado e contínuo, o que significa a abertura de novos assentamentos e/ou o surgimento de novos domicílios sem acesso à rede geral de água em favelas já urbanizadas. Todavia, e esse é o ponto enfatizado neste texto, nas favelas já consolidadas e com alto grau de acesso à rede geral, o abastecimento de água tende a ser precário, seja pelo motivo descrito acima, seja devido às debilidades dos arranjos político-institucionais que viabilizam o funcionamento dessas redes.

Com a finalidade de entender esse problema note-se que, para solicitar uma ligação domiciliar de água e/ou esgotos, geralmente são exigidos documentos que comprovem a regularidade do imóvel, como cópias do Registro Geral do Imóvel (RGI) ou do Imposto Predial e Territorial Urbano (IPTU). No entanto, a maior parte dos domicílios em favelas, exatamente por sua irregularidade, não tem essa documentação e por isso, o atendimento depende de arranjo político-institucional específico. ${ }^{11}$

No passado, as práticas de autoconstrução dos moradores de favelas receberam apoio da administração pública e de entidades filantrópicas, notadamente a Igreja Católica, para a realização de melhorias pontuais, como a instalação de bicas de água. No caso do Rio de Janeiro, as favelas mais antigas tiveram suas redes de água construídas através de práticas de mutirão comunitário, que abriram valas para passar a tubulação das redes de distribuição, tendo como fonte esses chafarizes (Rodrigues, 2016). Nesse arranjo, as associaçôes de moradores de favelas ocuparam papel de destaque, mediando as relaçóes entre a administração pública e os usuários dos serviços nas favelas. ${ }^{12}$ Em São Paulo, também foi observada a prática de instalação de "cavaletes" para ligações comunitárias (atendendo vários domicílios), muitas vezes com apoio de entidades filantrópicas, a partir do qual construíram-se, através de mutirôes, as canalizações de água para distribuição aos domicílios. ${ }^{13}$ Também ocorreram - e tendem a ocorrer sobretudo nas novas ocupaçóes -, com frequência, ligaçóes clandestinas de água em favelas.

Nesse ponto, é importante salientar que a construção das redes de infraestrutura em favelas e outros tipos de assentamentos irregulares foi concomitante à construção do direito à moradia para esse segmento habitacional em âmbito internacional, processo que influenciou a incorporação do direito à moradia na legislação nacional (Saule Junior, 2004). Vale lembrar que o direito à moradia está no rol de direitos humanos desde 1948, tendo sido enfatizado no Pacto Internacional para os

10. Disponivel em: <https://ondasbrasil.org/carta-aberta-a-sociedade-brasileira-ondas-e-a-epidemia-da-covid-19-no-brasil/> .

11. A documentação necessária para uma ligação domiciliar de água geralmente é informada nos sites das companhias de saneamento. No caso da Companhia de Saneamento Básico do Estado de São Paulo (Sabesp) e da Companhia Estadual de Água e Esgotos do Rio de Janeiro (Cedae), exige-se RGI ou IPTU. Para as favelas, ambas mantêm programas especiais de atendimento.

12. Mais detalhes em Rodrigues (2016).

13. Disponivel em: <http://www.ebanataw.com.br/4430/clubes/sptatuape/pla.htm>. 
Direitos Econômicos, Sociais e Culturais, de 1966, assinado pelo Brasil em 1992. Ainda no âmbito das Naçóes Unidas, a Declaração de Vancouver sobre Assentamentos Humanos (Habitat I), em 1976, orientou os países em desenvolvimento a adotarem políticas de urbanização de assentamentos precários e instalação de infraestruturas de saneamento básico, entre outras, estimulando a participação comunitária e o uso de mão de obra local em práticas do tipo mutirão (self-help aided programs). Em âmbito nacional, em 1978, criou-se o primeiro programa federal de urbanização de favelas, o Programa de Erradicação de Submoradias (Promorar), e em 1979, a Lei no 6.766 incluiu um artigo permitindo a adoção de normais flexíveis para a urbanização de assentamentos precários, que posteriormente seria utilizado para o demarcação de Zonas (ou Áreas) Especiais de Interesse Social (ZEIS). A Constituição de 1988 instituiu o usucapiấo urbano, garantindo a posse em áreas de favelas e, posteriormente, a moradia passou a figurar no rol dos direitos fundamentais, tal como expresso no art. $6^{\circ}$ da Constituição Federal. Além disso, o direito à moradia foi definido como um componente do direito a cidades sustentáveis definido na Lei no ${ }^{-10257 / 2001 ~(E s t a t u t o ~ d a ~ C i d a d e) ~ c o m o ~ u m ~}$ objetivo que reúne o "direito à terra urbana, à moradia, ao saneamento ambiental, à infraestrutura urbana”, entre outros fatores. Finalmente, cabe lembrar que, em 2010, o direito à água foi instituído como um direito humano fundamental pelas Naçóes Unidas.

Voltando ao histórico da construção das redes de água nos assentamentos precários, sobretudo a partir dos anos 1980, os governos estaduais, por meio de suas companhias de saneamento, passaram a empreender programas específicos para implantação de redes de água e esgotamento sanitário em favelas. No Rio de Janeiro, o Programa de Favelas da Cedae (Proface), iniciado em 1983, promoveu a instalação de modernas redes de distribuição de água, com sistema de bombeamento para reservatórios de alta capacidade no alto dos morros, implantando também sistemas de esgotamento sanitário (Verde, 2017). Em São Paulo, no mesmo período, a Sabesp desenvolveu metodologias específicas para a implantação de redes de água, adotando padróes diferenciados de equipamentos e tubulaçóes para os becos e vielas (Moreira, 2008). Também ocorreram extensos programas de implantação de redes de água e esgotamento em favelas da região do ABC Paulista, desenvolvidos pelos serviços públicos municipais (Cardoso e Denaldi, 2018). Em Pernambuco, as áreas pobres também passaram a ser atendidas pela companhia estadual de saneamento nos anos 1980 (Ferreira, Ramos e Bernardes, 2015). A partir de 1985, o governo federal passou a financiar os investimentos em saneamento básico em áreas de favelas, por meio do Programa de Abastecimento de Água e Esgotamento Sanitário para as Populaçôes de Baixa Renda em Áreas Urbanas (Prosanear).

Os programas de urbanização de favelas capitaneados pelas prefeituras, por sua vez, propuseram intervençôes mais amplas nos assentamentos, não apenas restritas às redes de infraestrutura, e foram adotados por um conjunto significativo de municípios desde a década de 1980. A experiência acumulada por equipes de profissionais em cada município gerou metodologias diferentes de intervenção urbana, contribuindo para a diversidade da forma dos assentamentos tal como os observamos na atualidade (Cardoso, 2007). Os projetos de urbanização de favelas realizados através do Programa de Aceleração do Crescimento (PAC), entre 2007 e 2014, tiveram como uma característica comum a ampliação da construção de novas unidades habitacionais, nas quais as ligaçóes às redes de infraestrutura têm padrão regular.

Embora não exista um levantamento específico sobre a construção das redes de abastecimento de água nas favelas, é possível deduzir que as redes de água são, atualmente, um misto/sobreposição dessas situaçóes diversas: i) ligaçôes realizadas por meio de mutiróes comunitários; ii) ligaçóes 
clandestinas; e iii) redes construídas pelas companhias de saneamento (estaduais) e/ou programas de urbanização de favelas (em geral, municipais). É possível que, muitas vezes, a rede seja regular, construída pelas companhias de saneamento ou pelas prefeituras, mas a ligação seja irregular, evidenciando a insuficiência de capacidade de pagamento pelo serviço; ou a ligação não tenha sido realizada, pela incapacidade de o usuário pagar pelo próprio ramal de ligaçáo (razáo pela qual alguns programas de urbanização de favelas incluíram o custo das ligaçóes para famílias de baixa renda entre os itens financiáveis). Nos casos de Rio de Janeiro e São Paulo, a gestão dessas redes se dá através de parcerias que podem envolver companhias de saneamento, empresas terceirizadas, associaçóes de moradores, prefeituras e governos do estado, em que muitas vezes a responsabilidade de cada um no arranjo náo é bem definida (Moreira, 2008; Verde, 2017).

Assim, embora seja verdade que boa parte das favelas consolidadas contam, em alguma medida, com acesso ao abastecimento de água, o arranjo político-institucional para a gestão desses serviços não é igual ao dos bairros regulares. Às dificuldades de gestão, somam-se outros problemas frequentes que ajudam a compreender as deficiências das redes de água nas favelas, como a inconclusão das obras de urbanização, a falta de manutenção das redes e o crescimento descontrolado dos assentamentos, sobretudo nos grandes complexos de favelas, assim como a insuficiência na adução de água para muitas destas áreas (Sampaio, 1991; Rodrigues, 2016; Cardoso e Denaldi, 2018; Ferreira, Ramos e Bernardes, 2015).

Voltando às manifestaçóes dos moradores de favelas exigindo o abastecimento de água no contexto da pandemia, observa-se que instrumentos jurídicos foram acionados, fundamentados no direito formal à moradia, tal como inscrito na legislação brasileira. No Rio de Janeiro, a Defensoria Pública e o Ministério Público estadual conseguiram uma liminar para que o governo e a prefeitura da capital, bem como a Cedae, providenciassem a regularização do fornecimento de água, principalmente nas áreas de favelas da cidade, com o abastecimento por caminhóes pipa, entre outras medidas. ${ }^{14}$ Em Sáo Paulo, a Promotoria de Justiça de Habitação e Urbanismo da Capital ajuizou ação civil pública pedindo a concessão de liminar para que a Sabesp e o governo estadual garantissem o abastecimento diário de água potável em todas as favelas paulistas, sendo a liminar concedida pelo Tribunal de Justiça (Amancio e Menon, 2020).

Assim, embora o arranjo institucional que viabiliza as redes de água em favelas seja um tanto quanto indefinido quanto às responsabilidades dos atores envolvidos, reconhece-se o direito da população ao acesso à água tratada, sendo a prefeitura, o governo do estado e as companhias estaduais acionadas como responsáveis.

Para concluir, podemos dizer que esta situação de pandemia colocou em evidência na imprensa e nas redes sociais os problemas que devem ser superados para a universalização da moradia adequada no Brasil, entre eles o acesso regular à água tratada. Neste texto, foram apresentadas evidências sobre os avanços das políticas de fornecimento de água em favelas e outros assentamentos precários nas últimas décadas, assim como a complexidade do arranjo político-institucional existente para atender a estas áreas. Se por um lado a atuação das companhias de saneamento básico - até então predominantemente controladas pelo estado -, apoiadas por investimentos federais em programas estaduais e municipais de urbanização de favelas, conseguiram promover o acesso à água tratada em boa parte das favelas, por outro lado, a disponibilidade diária da rede ainda não foi garantida.

14. Disponivel em: <https://coronavirus.rj.def.br/liminar-garante-abastecimento-de-agua-em-comunidades/>. 
Em termos mais gerais, reforça-se a ideia de que a atuação do Estado é central para a universalização da moradia adequada no Brasil, para a qual é imprescindível que haja políticas públicas abrangentes, planejadas e continuadas. No caso das favelas, já existe no país ampla experiência de gestão de projetos de urbanização que, aliados à construção de novas habitaçôes in loco, poderiam estabelecer os limites aceitáveis entre mais saneamento (abastecimento de água, esgotamento sanitário, drenagem e coleta de lixo) e menos liberdade construtiva, e oferecer projetos que podem ser bem recebidos pelos moradores e apoiados pelas organizaçóes sociais que atuam nas comunidades. Porém, para superar os limites atuais dos programas de habitação popular e urbanização de favelas, é preciso enfrentar a questão da produção e reprodução dos assentamentos precários, em especial o desafio de compor um arranjo político-institucional que assegure a qualidade das habitaçóes e das redes de infraestruturas, ao mesmo tempo que caminhe para universalização do direito à moradia.

\section{REFERÊNCIAS}

AMANCIO, T.; MENON, I. Liminar obriga Sabesp e governo de SP a fornecerem água a favelas de SP. Folha de Sáo Paulo, 7 abr. 2020.

BRITTO, A. L. Tarifas sociais e justiça social no acesso aos serviços de abastecimento de água e esgotamento sanitário no Brasil. In: CASTRO, J. E.; HELLER, L.; MORAIS, M. P. O direito à água como política pública na América Latina: uma exploração teórica e empírica. Brasília: Ipea, 2015. p. 209-226.

CARDOSO, A. L. Avanços e desafios na experiência brasileira de urbanização de favelas. Cadernos da Metrópole, n. 17, p. 219-240, 2007.

CARDOSO, A. L.; DENALDI, R. Urbanizaçáo de favelas no Brasil: um balanço preliminar do PAC. Rio de Janeiro: Letra Capital, 2018.

FERREIRA, H. M.; RAMOS, A. S.; BERNARDES, D. A. A política de racionamento de água na cidade do Recife, Brasil: impactos e desigualdades nos assentamentos precários. In: CASTRO, J. E.; HELLER, L.; MORAIS, M. P. O direito à água como política pública na América Latina: uma exploração teórica e empírica. Brasília: Ipea, 2015. p. 83-108.

MOREIRA, R. M. Distribuiçáo de água na regiáo metropolitana de Sáo Paulo: tecnologias da universalização e produção do espaço. 2008. Dissertação (Mestrado) - Universidade de São Paulo, São Paulo, 2008.

OLIVEIRA, R. M.; VALLA, V. V. As condições e as experiências de vida de grupos populares no Rio de Janeiro: repensando a mobilização popular no controle da dengue. Cadernos de Saúde Pública, n. 17, p. 77-88, 2001.

RODRIGUES, R. I. Uma construção complexa: necessidades básicas, movimentos sociais, governo e mercado. In: ___ Vida social e política nas favelas: pesquisas de campo no Complexo do Alemão. Rio de Janeiro: Ipea, 2016. 
A Covid-19, a falta de água nas favelas e o direito à moradia no Brasil. Brasília: Ipea, 2020. (Nota Técnica, n. 39).

SAMPAIO, M. R. Heliópolis: o percurso de uma invasão. 1991. Tese (Livre-Docência) - Universidade de São Paulo, São Paulo, 1991.

SANTOS JÚNIOR, O. A.; MONTANDON, D. T. Os planos diretores municipais pós-Estatuto da Cidade: balanço crítico e perspectivas. Rio de Janeiro: Letra Capital, 2011.

SAULE JUNIOR, N. (2004). A proteção jurídica da moradia nos assentamentos irregulares. Porto Alegre: Sergio Antônio Fabris Editor, 2004.

VERDE, M. T. Saneamento básico em comunidades de baixa renda no estado do Rio de Janeiro, aspectos institucionais e gerenciais. In: CONGRESSO INTERAMERICANO DE ENGENHARIA SANITÁRIA E AMBIENTAL, 28., 2017, Rio de Janeiro. Anais... Rio de Janeiro: ABES, 2017. 
